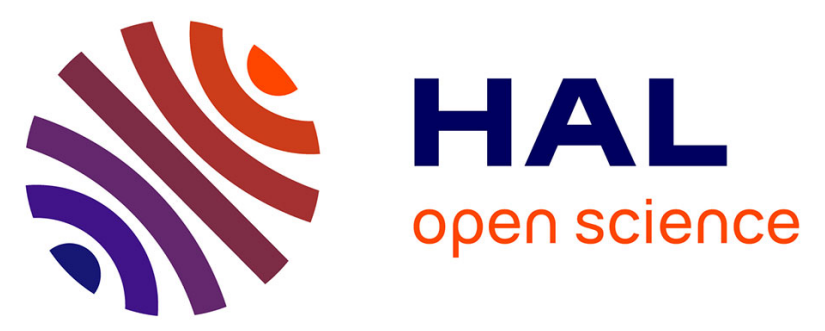

\title{
The Btk-dependent PIP5K1 $\gamma$ lipid kinase activation by Fas counteracts FasL-induced cell death
}

Aurélie Rossin, Nadia Lounnas, Jérôme Durivault, Giorgia Miloro, Laurent Gagnoux-Palacios, Anne-Odile Hueber

\section{To cite this version:}

Aurélie Rossin, Nadia Lounnas, Jérôme Durivault, Giorgia Miloro, Laurent Gagnoux-Palacios, et al.. The Btk-dependent PIP5K1 $\gamma$ lipid kinase activation by Fas counteracts FasL-induced cell death. Apoptosis, 2017, 22 (11), pp.1344 - 1352. 10.1007/s10495-017-1415-x . hal-03516413

\section{HAL Id: hal-03516413 \\ https://hal.science/hal-03516413}

Submitted on 21 Jan 2022

HAL is a multi-disciplinary open access archive for the deposit and dissemination of scientific research documents, whether they are published or not. The documents may come from teaching and research institutions in France or abroad, or from public or private research centers.
L'archive ouverte pluridisciplinaire HAL, est destinée au dépôt et à la diffusion de documents scientifiques de niveau recherche, publiés ou non, émanant des établissements d'enseignement et de recherche français ou étrangers, des laboratoires publics ou privés. 
The Btk-dependent PIP5K1Y lipid kinase activation by Fas counteracts FasL-induced cell death

Aurélie Rossin ${ }^{1 \S}$, Nadia Lounnas ${ }^{1 \S}$, Jérôme Durivault ${ }^{1}$, Giorgia Miloro ${ }^{1}$, Laurent Gagnoux-Palacios ${ }^{1}$, and Anne-Odile Hueber ${ }^{1, *}$

${ }^{1}$ Université Côte d'Azur, CNRS, Inserm, iBV, France.

${ }^{\S}$ These authors contributed equally to this work.

* Corresponding author: AO Hueber, Université Côte d'Azur, Institut de Biologie Valrose, CNRS UMR 7277, Inserm UMR 1091, Parc Valrose, Bâtiment des Sciences Naturelles, 06108 Nice Cedex2, France. hueber@unice.fr.

Total character count: 4269 words 


\section{Abstract}

The Fas/FasL system plays a critical role in death by apoptosis and immune escape of cancer cells. The Fas receptor being ubiquitously expressed in tissues, its apoptotic-inducing function, initiated upon FasL binding, is tightly regulated by several negative regulatory mechanisms to prevent inappropriate cell death. One of them, involving the non-receptor tyrosine kinase Btk, was reported mainly in B cells and only poorly described. We report here that Btk negatively regulates, through its tyrosine kinase activity, the FasL-mediated cell death in epithelial cell lines from colon cancer origin. More importantly, we show that Btk interacts not only with Fas but also with the phosphatidylinositol-4-phosphate 5-kinase, PIP5K1Y, which, upon stimulation by Fas ligand, is responsible of a rapid and transient synthesis of phosphatidylinositol-4,5-bisphosphate $\left(\mathrm{PI}(4,5) \mathrm{P}_{2}\right)$. This production requires both the presence and the tyrosine kinase activity of Btk, and participates in the negative regulation of FasL-mediated cell death since knocking down PIP5K1 $\gamma$ expression significantly strengthens the apoptotic signal upon FasL engagement. Altogether, our data demonstrate the cooperative role of Btk and PIP5K1Y in a FasL-induced $\mathrm{PI}(4,5) \mathrm{P}_{2}$ production, both proteins participating to the threshold setting of FasL-induced apoptotic commitment in colorectal cell lines.

Keywords: Fas / Btk / PIP5K1Y / PI(4,5) $\mathrm{P}_{2}$ / cell death 


\section{Introduction}

Fas (CD95, TNFRSF6) is a death receptor which belongs to the TNF (tumor necrosis factor) receptor superfamily. Its engagement by its natural ligand Fas Ligand (FasL, CD95L, TNFSF6), results in apoptotic signaling through recruitment of the adaptor protein FADD which in turn binds the procaspases $8 / 10$, leading to a molecular platform named the death-inducing signaling complex (DISC) [1]. Within the DISC, upstream caspases are activated and initiate a caspase cascade which leads to cell destruction [2]. This death-inducing function plays an important role in tissue homeostasis notably via elimination by the immune system of obsolete, damaged or dangerous cells such as cancer cells [3]. In addition Fas can transduce alternative non-death signaling supporting cell survival, inflammation or migration in physiological or pathological context [4].

Fas is ubiquitously expressed in human tissue and its activation needs to be tightly regulated to avoid inappropriate cell death. Most tumor cells express Fas and develop resistance to FasL-induced cell death to escape from immune-surveillance. In both physiological and pathological conditions, several negative regulators occurring at different stages of the Fas signaling have been identified as able to increase the Fas activation threshold such as Fap-1 [5], Shp-1 [6], c-Flip [7] or Btk [8]. We addressed here the role of one of these Fas negative regulators, the kinase Btk, in the resistance of epithelial colorectal cancer cells to FasL-induced cell death.

Btk, a member of the Tec family of non-receptor tyrosine kinase, is a well-known regulator of the B cell lineage controlling the survival, activation, proliferation and differentiation of the B cells. At a molecular level, Btk interacts with a plethora of proteins critical for the regulation of the signaling pathways activated by surface receptors such as the $\operatorname{BCR}$ or $\operatorname{TLR}$ family $[9,10]$. In addition, Btk seats on a critical node in phosphoinositide signaling, harboring a Pleckstrin Homology (PH) domain with high affinity for phosphatidylinositol-3,4,5-triphosphate $\left(\mathrm{PI}(3,4,5) \mathrm{P}_{3}\right)$ binding which is a prerequisite for its activation [10]. Moreover, Btk is necessary for phosphatidylinositol-4,5-bisphosphate 
$\left(\mathrm{PI}(4,5) \mathrm{P}_{2}\right)$ synthesis upon $\mathrm{BCR}$ activation through its ability to bind phosphatidylinositol-4-phosphate 5-kinase $1 \gamma(\mathrm{PIP5K} 1 \gamma)$, an enzyme catalyzing $\mathrm{PI}(4,5) \mathrm{P}_{2}$ production [11].

Currently, the Btk inhibitor Ibrutinib is approved for the treatment of three B-cells malignancies including chronic lymphoid leukemia [12]. Btk expression and functions were reported outside the B hematopoietic system including in epithelial cancer cells (breast, prostate, and colon) where it displays oncogenic properties [13-15]. However, its negative role on FasL-induced cell death was only reported in B cells and explained by a constitutive Fas/Btk interaction. In this study, we reveal a new molecular axis, Fas-Btk-PIP5K1Y, used to counteract the FasL-induced cell death in colon cancer cells. We not only identify Btk as a critical linker between Fas and PIP5K1Y, but also demonstrate that PIP5K1Y, via its Btk-dependent recruitment to Fas, stimulates the production of $\mathrm{PI}(4,5) \mathrm{P}_{2}$ and reveal PIP5K1Y as a Fas negative regulator in colon cancer cells.

\section{Results}

\section{Btk negatively regulates FasL-induced cell death in colon cancer cells.}

Since the functional involvement of Btk on FasL-induced cell death has never been addressed in an epithelial context, we studied this role in colorectal epithelial cells. Immunoblot analysis shows that Btk is expressed in different colon cancer cell lines and appears as a main band of $78 \mathrm{kDa}$ with an additional band at $80 \mathrm{kDa}$ in some cell lines (Fig.1a), both targeted by specific Btk siRNA (supplementary Fig.1a). Of note, an alternative Btk protein of $65 \mathrm{kDa}$ has been described by one research group in colorectal cell lines but we could not detect it in our experimental conditions [13].Knocking down Btk expression significantly increases FasL-induced apoptosis in the four cell lines tested (SW480, HCT15, SW48, HT29) as measured by the production of sub-G1 particles detected by flow cytometry (Fig.1b). Interestingly, the death induced by TRAIL (TNF-related apoptosis inducing ligand), another death ligand of the TNFa superfamily is also increased in colorectal cell lines upon 
Btk silencing (supplementary Fig. 1b). The enhanced FasL-induced cell death was confirmed at a biochemical level by an increased cleavage of both the initiator caspase 8 and the executioner caspase target PARP (Fig.1c). Thus, Btk plays a role to negatively regulate Fas-mediated cell death in the epithelial colorectal cells.

Btk was described to have both kinase dependent and independent functions [16]. In order to study the influence of its kinase activity on this regulation, we exposed the colorectal cancer cell lines to two well described specific Btk inhibitors, LFM-A13 and Ibrutinib. We showed that inhibiting Btk kinase activity increases FasL-induced cell death (Fig 1d-e and supplementary Fig1) and TRAILinduced cell death (supplementary Fig.1c), demonstrating that the kinase activity of Btk is necessary for its inhibitory function on death receptor-mediated apoptosis.

\section{Fas interacts with Btk and PIP5K1Y}

In order to further dissect at the molecular level the Btk inhibitory function on FasL-induced cell death, we transfected both Btk and Fas in 293T cells. We show, as it was reported in B cells, that Fas co-immunoprecipitates with Btk (Fig.2a) and vice-versa (Fig.2b). Since it was demonstrated in B cells that Btk could interact with PIP5K1Y to mediate BCR signaling, we decided to test the potential involvement of this lipid kinase in the anti-apoptotic role played by Btk on FasL-induced cell death. We confirmed the Btk-PIP5K1Y interaction in 293T cells (Fig.2a). More importantly, while Fas and PIP5K1 $\gamma$ weakly interact when expressed in 293T (Fig.2b, detected only in high exposure condition), their interaction increases upon Btk co-expression (Fig.2b) independently of the nature of the PIP5K1Y isoform expressed (p87, p90 or both), showing that Btk is a link between Fas and PIP5K1Y within the same protein complex. In order to study the requirement of the PIP5K kinase activity in this interaction, we generated kinase dead mutant of both PIP5K1Y isoforms and show that they are still able to immunoprecipitate with Fas (Fig.2b) demonstrating that the kinase activity of PIP5K1Y was not necessary to interact with the Fas/Btk complex. 
Using a genetic approach, we interrogate whether Btk kinase activity is necessary for its interaction with Fas by expressing in 293T cells together with Fas and PIP5K1Y, a kinase dead mutant of Btk (Btk K430R). We show that the interaction between Btk K430R and Fas is impaired and therefore prevents the recruitment of PIP5K1Y to Fas (Fig.2a). This result was confirmed using a pharmacological approach: the Btk inhibitor treatment Ibrutinib abolishes the formation of the protein complex (Fig.2c). We then concluded that the kinase activity of Btk is necessary for the formation of a protein complex containing Fas, Btk and PIP5K1ץ.

\section{Fas activation induces a rapid and transient $\mathrm{PI}(4,5) \mathrm{P} 2$ production}

As we demonstrated that Btk connects Fas to the lipid kinase PIP5K1Y, we hypothesize that a PIP5K1 $\gamma$-dependent $\mathrm{PI}(4,5) \mathrm{P}_{2}$ production might occur upon FasL exposure. We monitored by flow cytometry analysis this lipid level in SW480 cells upon FasL treatment using specific anti $\mathrm{PI}(4,5) \mathrm{P}_{2}$ antibody. We observed a rapid and transient $\mathrm{PI}(4,5) \mathrm{P}_{2}$ production as soon as 5 min of FasL treatment which culminates at $10 \mathrm{~min}$ of activation to come back to a basal level after $15 \mathrm{~min}$ (Fig. 3a). Importantly, this increase in $\mathrm{PI}(4,5) \mathrm{P}_{2}$ intracellular content is abolished when PIP5K1Y is knocked down (Fig. 3a) suggesting that the FasL-induced $\mathrm{PI}(4,5) \mathrm{P}_{2}$ increase comes from a PIP5K1 1 -mediated $\mathrm{PI}(4,5) \mathrm{P}_{2}$ production and not from a decrease in $\mathrm{PI}(4,5) \mathrm{P}_{2}$ consumption.

Importantly, the same type of inhibition was also found when Btk expression was knocked down (Fig. 3a) thus confirming at the functional level the requirement of Btk to bridge PIP5K1Y to the Fas receptor. Finally, inhibiting the Btk kinase activity using LFM-A13 or ibrutinib inhibitors prevents this FasL-mediated $\mathrm{PI}(4,5) \mathrm{P}_{2}$ production (Fig. 3b). Altogether, our data demonstrate that the PIP5K1Y recruitment to Fas through the protein kinase Btk allows the FasL-mediated $\mathrm{PI}(4,5) \mathrm{P}_{2}$ production.

\section{PIP5K1Y negatively regulates FasL-induced cell death}

In order to establish whether the PIP5K1 $\gamma$-mediated $\mathrm{PI}(4,5) \mathrm{P}_{2}$ production participates in the negative role of Btk on FasL-induced cell death, we generated SW480 stable cell lines expressing shRNA 
targeting PIP5K1 $\gamma$ (SW480 shPIP5K1Y) or a scramble shRNA as control (SW480 shCtrl). We verified the efficiency of the PIP5K1Y knock down (which affects both p87 and p90 isoforms) and the equivalent total and cell surface Fas expression level in both cell lines (Fig.4a). We showed, based on the appearance of sub-G1particles (Fig.4b) and the cleavage of caspase 8 (Fig.4c) that knocking down PIP5K1Y expression considerably increases FasL-induced cell death.

In order to test the influence of PIP5K1Y on FasL-induced cell death in a more physiological context, we co-cultured the SW480 shPIP5K1Y or the SW480 shCtrl with the REH killer cells which stably express FasL on their surface. As seen in Fig. 4d, the SW480 shPIP5K1ץ cells are more prone to die than their control counterparts. Importantly, we confirmed that silencing PIP5K1Y by siRNA in SW480 but also in SW48, HT29 and HCT15 enhances FasL-induced cell death (Fig.4e and supplementary Fig. 2a). Moreover, PIP5K1 $\gamma$ knock down also increases TRAIL-induced cell death to the same extend than FasL (supplementary Fig.2b). Our data demonstrating that PIP5K1y knock down significantly increases FasL-mediated cell death firmly identified PIP5K1Y as a Fas negative regulator in colon epithelial cells.

\section{Discussion}

Btk belongs to the Tec tyrosine kinases family characterized by the ability of its members to bind both proteins and membrane phospholipids through a $\mathrm{PH}$ domain. These interactions lead to the formation of lipid-protein complexes known to play a critical role in several signal transduction processes including regulation of cell death [10]. The Btk involvement in the Fas signaling was so far only studied in cells from hematopoietic origin and demonstrated to play an inhibitory role on the death signaling in $B$ cells $[8,17]$ whereas no role were found in Fas-mediated death in macrophages [18]. Molecularly, Btk has been reported to associate with the death receptors Fas in B cells and TRAIL-R1 in erythroid progenitors $[8,19]$. No studies were performed in a non-immune context. We reveal here the inhibitory role of Btk in FasL-induced epithelial cell death showing that Btk knock 
down increases FasL susceptibility in SW480 cells and that Btk kinase activity is required to maintain a constitutive interaction between Fas and Btk and therefore its inhibitory effect. The requirement of Btk kinase activity for Fas association led us hypothesize that Fas could be a Btk substrate but we could not detect any increase of Fas tyrosine phosphorylation upon BTK overexpression or FasL activation (data not shown).

More importantly, we dissect at a molecular level the Btk's role as a Fas negative regulator by demonstrating its critical linker position to brings to Fas a so far unknown partner of the death receptor, the PIP5K1Y. We reported that PIP5K1Y is activated upon FasL stimulation and leads to a rapid increase of $\mathrm{PI}(4,5) \mathrm{P}_{2}$ intracellular level. Although a localized $\mathrm{PI}(4,5) \mathrm{P}_{2}$ production by $\mathrm{PIP5K}$ was reported following activation of several membrane receptors, as integrins [20], BCR [11] or EGFR [21], our data describe for the first time such lipid production upon a death receptor engagement. $\mathrm{PI}(4,5) \mathrm{P}_{2}$ is a minor lipid in membranes but is a key signaling molecule [22]. Several hypothesis concerning the role that $\mathrm{PI}(4,5) \mathrm{P}_{2}$ could play on keys events of the death receptor signaling can be considered. We can first speculate that the $\mathrm{PI}(4,5) \mathrm{P}_{2}$ production might participate to the transduction of a FasL-induced survival pathway requiring a clathrin-dependent endocytosis (CDE) which was reported by several groups including ours $[23,24]$, given that $\mathrm{PI}(4,5) \mathrm{P}_{2}$ can regulate the activity of clathrin adaptors such as AP-2, epsin or AP180 [25]. Secondly, the Fas-mediated $\mathrm{PI}(4,5) \mathrm{P}_{2}$ production could activate Ezrin, an adaptator protein linking the membrane receptors to the actin cytoskeleton and containing a $\mathrm{PI}(4,5) \mathrm{P}_{2}$ binding motif since the importance of Ezrin in FasL-induced cell death has been validated in several studies [26-28]. Finally, as the $\mathrm{PI}(4,5) \mathrm{P}_{2}$ level decreases after 10 min of FasL treatment, it might be consumed by several enzymes including PI3Kinase which generates $\mathrm{PI}(3,4,5) \mathrm{P}_{3}$, a second messenger known to bind and activate several $\mathrm{PH}$ domain-containing proteins such as Akt and Btk itself. The PI3K/Akt axis has been reported to negatively regulate FasL-induced cell death by acting at early stage of the Fas signaling and we previously showed that inhibition of the $\mathrm{PI} 3 \mathrm{~K} /$ Akt axis potentiates FasL-induced apoptosis in colon cancer cells [29]. Thus, $\mathrm{PI}(4,5) \mathrm{P}_{2}$ might be converted into $\mathrm{PI}(3,4,5) \mathrm{P}_{3}$ to activate the Akt-dependent Fas inhibitory pathway, or activate 
additional Btk proteins to create an amplification loop. Further studies will be necessary to decipher the complex role of this $\mathrm{PI}(4,5) \mathrm{P}_{2}$ produced upon FasL stimulation in a Btk/PIP5K1 $\gamma$-mediated pathway. Additionally, our work provide results showing that knocking down both Btk and PIP5K1Y increases TRAIL-induced cell death in different colon cells. This strongly implies that the Btk/PIP5K1Y axis plays an important role in TRAIL receptor-mediated signaling and open interesting perspective for this work, including the dissection of the molecular mechanism involved.

Altogether, our results suggest that the negative role of the Btk/PIP5K1Y axis on FasL-induced cell death is not limited to impairment of optimal death signaling but also might allow the activation of a pro survival signal which could be mediated by the production of $\mathrm{PI}(4,5) \mathrm{P}_{2}$. The outcome of both signaling results in blocking early events of FasL-induced cell death since the cleavage of the upstream caspase 8 is affected. Interestingly, a recent report underlie the importance of Btk recruitment and activation in FasL-induced cell rolling and adhesion in myeloid cells, thus confirming that Btk might be also able to transduce a FasL-induced non-death signal in some defined contexts [30]. Finally, in a therapeutic perspective, inhibiting Btk with specific drugs such as Ibrutinib could help restoring cell death in cancer cells that have develop resistance to FasL-induced cell death during tumorigenesis.

\section{Material and methods}

\section{Constructs}

The kinase dead (KD) constructs of PIP5K1Y (K188R K200R) and of Btk (K430R) were obtained by sitedirected mutagenesis using the pLenti4 PIP5K1Y-V5 and pSR-HA-Btk (mouse) as templates and the following primers:

CAAGACCGTTATGCATAAGGAGGCCG (forward PIP5K1ץ KD) 
CGGCCTCCTTATGCATAACGGTCTTG (reverse PIP5K1Y KD)

GATGTGGCCATCAGGATGATCAGAGAAGGTTC (forward Btk KD)

GAACCTTCTCTGATCATCCTGATGGCCACATC (reverse Btk KD)

pLVTH-shcontrol or pLVTH-shPIP5K1C were obtained by cloning shRNAi sequence of human PIP5K (AAGACCGTCATGCACAAGGA)or Scramble (CCTAAGGTTAAGTCGCCCTCG) into pLVTH plasmids.

\section{Cell culture, treatment and transfection}

SW480 (ATCC CLL-228), HCT15 (DSMZ ACC357), HT29 (DSMZ ACC299), SW48 (ATCC CLL-231) and REH pcR33FasL cells were grown in RPMI 10\% fetal calf serum up to passage 20 and HEK293T in DMEM $10 \%$ fetal calf serum.

pLVTH-shCtrl or pLVTH-shPIP5K1C were cotransfected into HEK293T cells with the lentivirus packaging plasmids p8.91 and pMD2.G. Collected supernatants were applied on SW480 cells with polybrene $(8 \mu \mathrm{g} / \mathrm{ml})$. Infected cells were selected by Blasticidin treatment $(1 \mu \mathrm{g} / \mathrm{ml}$, Invivogen).

Transient transfection of siRNA was obtained by using the RNAimax transfection reagent. Si PIP5K1ץ or siRNA scramble come from Quiagen. Si BTK is a pool of 4 different sequences coming from Dharmacon. Transient transfection of plasmids was done with Jetprime transfection reagent (Polyplus-transfection).

\section{Cell death assay}

SW480 cells were incubated with indicated doses of recombinant human Flag-FasL or recombinant Flag-TRAIL (Alexis, SanDiego, USA) crosslinked with $1 \mu \mathrm{g} / \mathrm{ml} \mathrm{M} 2$ anti-Flag antibody (Sigma, SaintLouis, USA). Alternatively, SW480 cells were cocultured with FasL-expressing REH killer cells prestained with $1 \mu \mathrm{M}$ diacetate succinimidyl ester (CFSE) prior the coculture. Cells were harvested,

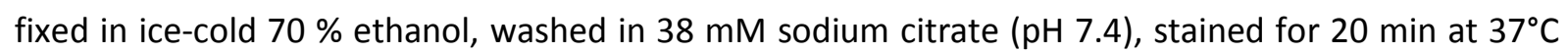
with $50 \mu \mathrm{g} / \mathrm{ml}$ propidium iodide (Sigma, Saint-Louis, USA) and $5 \mu \mathrm{g} / \mathrm{ml}$ RNaseA (Sigma, Saint-Louis, 
USA) in $38 \mathrm{mM}$ sodium citrate and analysed by flow cytometry using the Fortessa analyser (Becton Dickinson). The proportion of apoptotic cells as represented by the sub-G1 peak was determined.

\section{Immunoblotting}

Immunoblot analysis of total proteins was performed according to standard protocols. Upon lysis with Laemmli buffer, proteins were resolved by SDS-PAGE, followed by transfer to a PVDF membrane (Immobilon-P; Millipore). Immunoblotting was performed using indicated primary antibodies and HRP-coupled secondary antibody (Jackson ImmunoResearch). Anti Btk, anti-PIP5K1Y, anti-caspase 8 (clone 1C12) and anti-PARP antibodies were from Cell signalling technology (Danvers, USA), anti Fas antibody (rabbit monoclonal EPR5700) was from Abcam (Cambridge, United Kingdom), anti-cleaved caspase 3 antibody was from BD biosciences (Franklin Lakes, USA), anti-Ezrin antibody (clone 3C12) was from Zymed, anti-GAPDH antibody was from Merck Millipore (Darmstadt, Germany) and antiactin antibody was from Sigma (Saint-Louis, USA)

\section{Immunoprecipitation}

Cells were lysed with buffer A (25 mM Hepes, 150 mM NaCl, 1 mM EGTA, 10 mM NaF, 10 mM Napyrophosphate, $5 \mathrm{mM}$ sodium orthovanadate, protease inhibitors cocktail) containing $1 \%$ NP-40 and $10 \%$ glycerol (lysis buffer) at $4{ }^{\circ} \mathrm{C}$. Lysates were incubated with the anti-Fas antibody Apo1.3 (Enzo Life sciences, Farmingdale, New York) or the anti-HA antibody (clone 16B12, Covance, Berkeley, USA) coupled to protein G-sepharose beads (Zymed, San Francisco, USA) for 4 hours. After 4 washes with lysis buffer, beads were eluted with Laemmli buffer at $95^{\circ} \mathrm{C}$ for $5 \mathrm{~min}$ and subjected to immunoblotting analysis.

\section{Flow cytometry analysis of Fas surface expression}

SW480 cells were harvested and incubated on ice with anti-Fas antibody DX2 conjugated with phycoerythrin (Miltenyi Biotech) for 30 minutes. Acquisition and analysis were performed on a Fortessa cytometer (Becton Dickinson). 


\section{$\mathrm{PI}(4,5) \mathrm{P}_{2}$ staining}

SW480 cells were stimulated with $50 \mathrm{ng} / \mathrm{ml} \mathrm{FasL} \mathrm{crosslinked} \mathrm{with} 1 \mu \mathrm{g} / \mathrm{ml} \mathrm{M} 2$ during indicated time, harvested and fixed for $30 \mathrm{~min}$ at room temperature in PBS containing $4 \%$ paraformaldehyde, $0.2 \%$ glutaraldehyde and $1 \%$ sucrose. Fixed cells were permeabilized with $10 \mu \mathrm{g} / \mathrm{ml}$ digitonin for 45 min and incubated with $\mathrm{PI}(4,5) \mathrm{P}_{2}$ primary antibody (clone 2C11, Echelon, Salt Lake City, USA-) overnight at $4{ }^{\circ} \mathrm{C}$ under agitation. After incubation with Alexafluor 546-conjugated anti-mouse IgM and fixation with PBS containing $2 \%$ paraformaldehyde the cells were analyzed on a flow cytometer (LSR Fortessa, BD).

\section{Figure legends}

Fig.1 - Btk negatively regulates FasL-induced cell death in colon cancer cells.

(a) Immunoblot showing Btk expression in colorectal cell lines.

(b) Indicated cells, transfected for 72 hours with si RNA Ctrl or si RNA Btk, were subjected for 5 hours to FasL (indicated doses of FasL $\mathrm{ng} / \mathrm{ml}+\mathrm{M} 2$ ) before flow cytometry analysis of sub-G1 particles. (c) SW480 cells transfected for 72 hours with si RNA Ctrl or si RNA Btk were exposed for 3 hours to FasL ( $25 \mathrm{ng} / \mathrm{ml}$ ) before lysis. Caspase 8 and PARP cleavage was determined by immunoblot as molecular features of cell death. Arrows indicate the cleaved forms of the proteins.

(d) SW480 cells pre-treated for 2 hours with DMSO, LFM-A13 $(50 \mu \mathrm{M})$ and Ibrutinib $(3 \mu \mathrm{M})$ were incubated for 5 hours with increasing doses of FasL. The percentage of cell death was assessed by flow cytometry quantification of sub-G1 particles.

(e) SW480 cells pre-incubated for 2 hours with DMSO, LFM-A13 $(50 \mu \mathrm{M})$ or Ibrutinib $(3 \mu \mathrm{M})$ were treated for 3 hours with $25 \mathrm{ng} / \mathrm{ml}$ FasL crosslinked with M2 and lysed for immunoblot analysis. 
Fig. 2 - Fas interacts with Btk and PIP5K1Y. 293T cells transiently expressing Fas, HA-tagged Btk and PIP5K1 $\gamma$ were lysed for co-immunoprecipitation experiments. PIP5K1 $\gamma$ is represented by an equal mix of p87 and p90 isoforms either wild type or kinase dead (KD) forms unless specified. Protein lysate were immunoprecipitated with anti HA antibodies (a) or anti Fas antibodies (b and c). PIP5K1 $\gamma$, Fas, and Btk were detected by immunoblotting. The requirement of Btk kinase activity was investigated by using the KD mutant K430R or by exposing the cells to Ibrutinib $(1 \mu \mathrm{M})$ for 2 hours before lysis (c). Fig.3 - Fas activation stimulates a Btk/PIP5K1Y-dependent $\mathrm{PI}(4,5) \mathrm{P}_{2}$ production. SW480 cells transfected for 72 hours with siRNA control, siRNA Btk, or siRNA PIP5K1Y (a) or pre-incubated for 2 hours with DMSO, LFM-A13 $(50 \mu \mathrm{M})$ or Ibrutinib $(3 \mu \mathrm{M})$ (b) were exposed to $50 \mathrm{ng} / \mathrm{ml}$ FasL crosslinked with $\mathrm{M} 2$. Upon fixation, cells were stained with a specific $\mathrm{PI}(4,5) \mathrm{P}_{2}$ antibody and analyzed by flow cytometry. The relative $\mathrm{PI}(4,5) \mathrm{P}_{2}$ intracellular content was represented as percentage of the non-activated control.

Fig.4 - PIP5K1ץ negatively regulates FasL-induced cell death.

(a) The efficiency of the PIP5K1Y knock down was assessed by immunoblot on SW480 shCtrl and SW480 shPIP5K1Y. The total and cell surface Fas expression were evaluated by immunoblot and flow cytometry analysis.

(b) SW480 shCtrl and SW480 shPIP5K1ץ cells were exposed for 6 hours to FasL treatment. Cell death was quantified by flow cytometry quantification of sub-G1 particles.

(c) SW480 shCtrl and SW480 shPIP5K1ץ cells were exposed for 3 hours to $25 \mathrm{ng} / \mathrm{ml}$ FasL crosslinked with $\mathrm{M} 2$ and lysed. Caspase 8 cleavage was monitored by immunoblot

(d) SW480 shCtrl and SW480 shPIP5K1Y target cells were co-cultured for 16 hours with the FasL expressing killer cells REH at different target to killer ratios. Target cell death was evaluated by flow cytometry quantification of sub-G1 particles after exclusion of the CFSE stained killer cells. 
(e) Colorectal cells, transfected for 72 hours with si RNA Ctrl or si RNA PIP5K1ץ, were subjected for 5 hours to FasL (indicated doses of Fas $\mathrm{ng} / \mathrm{ml}+\mathrm{M} 2$ ) before flow cytometry analysis of sub-G1 particles.

Supplementary Fig.1. (a) Efficient Btk knock down was assessed by immunoblot in the indicated cell lines. (b) HCT15, HT29 and SW48 cells transfected with Btk si RNA were exposed to indicated doses of TRAIL crosslinked with $\mathrm{M} 2(1 \mathrm{ng} / \mathrm{ml})$ and the percentage of cell death was determined by flow cytometry quantification of sub-G1 particles. (c) SW48, HT29 and HCT15 cells pre-treated for 2 hours with DMSO or Ibrutinib (1 and $3 \mu \mathrm{M}$ ) were incubated for 5 hours with indicated doses of FasL or TRAIL crosslinked with M2 $(1 \mu \mathrm{g} / \mathrm{ml})$. The percentage of cell death was assessed as in b..

Supplementary Fig.2. (a) Efficient PIP5K1Y knock down was assessed by immunoblot in the indicated cell lines. (b) HCT15 and HT29 cells transfected with PIP5K1Y si RNA were exposed to indicated doses of TRAIL crosslinked with $\mathrm{M} 2(1 \mu \mathrm{g} / \mathrm{ml})$ and the percentage of cell death was determined by flow cytometry quantification of sub-G1 particles.

\section{Acknowledgements}

We are grateful to Bernard Payrastre for discussion and input at the initial phase of this work, to Marcel Deckert for providing us the mouse Btk expression vector and to Sébastien Huault for technical assistance. The authors acknowledge Agnès Loubat (Plateforme de Cytométrie Cyan, iBV, Université Côte d'Azur) for advises and assistance.

This work was supported by institutional funds from the Centre National de la Recherche Scientifique (CNRS), the Institut National de la Santé et de la Recherche Medicale (Inserm) and by grants from the Institut national du cancer (INCa) (Grant No.2009-197) and the Agence Nationale de la Recherche (ANR) (Grant No. ANR-10-BLAN-1226; LABEX SIGNALIFE program Grant No.ANR-11-LABX-0028-01). 


\section{References}

1. Kischkel FC, Hellbardt S, Behrmann I, et al. (1995) Cytotoxicity-dependent APO-1 (Fas/CD95)associated proteins form a death-inducing signaling complex (DISC) with the receptor. EMBO J 14:5579-5588.

2. Krammer PH. (2000) CD95's deadly mission in the immune system. Nature 407:789-795.

3. Ehrenschwender M, Wajant H. (2009) The role of FasL and Fas in health and disease. Adv Exp Med Biol 647:64-93.

4. Peter ME, Budd RC, Desbarats J, et al. (2007) The CD95 receptor: apoptosis revisited. Cell 129:447-450.

5. Sato T, Irie S, Kitada S, Reed JC. (1995) FAP-1: a protein tyrosine phosphatase that associates with Fas. Science 268:411-415.

6. Daigle I, Yousefi S, Colonna M, Green DR, Simon HU. (2002) Death receptors bind SHP-1 and block cytokine-induced anti-apoptotic signaling in neutrophils. Nat Med 8:61-67.

7. Irmler M, Thome M, Hahne M, et al. (1997) Inhibition of death receptor signals by cellular FLIP. Nature 388:190-195.

8. Vassilev A, Ozer Z, Navara C, Mahajan S, Uckun FM. (1999) Bruton's tyrosine kinase as an inhibitor of the Fas/CD95 death-inducing signaling complex. J Biol Chem 274:1646-1656.

9. López-Herrera G, Vargas-Hernández A, González-Serrano ME, et al. (2014) Bruton's tyrosine kinase--an integral protein of $B$ cell development that also has an essential role in the innate immune system. J Leukoc Biol 95:243-250.

10. Mohamed AJ, Yu L, Bäckesjö CM, et al. (2009) Bruton's tyrosine kinase (Btk): function, regulation, and transformation with special emphasis on the PH domain. Immunol Rev 228:58-73.

11. Saito K, Tolias KF, Saci A, et al. (2003) BTK regulates Ptdlns-4,5-P2 synthesis: importance for calcium signaling and PI3K activity. Immunity 19:669-678.

12. Smith Cl. (2016) From identification of the BTK kinase to effective management of leukemia. Oncogene.

13. Grassilli E, Pisano F, Cialdella A, et al. (2016) A novel oncogenic BTK isoform is overexpressed in colon cancers and required for RAS-mediated transformation. Oncogene 35:4368-4378.

14. Guo W, Liu R, Bhardwaj G, et al. (2014) Targeting Btk/Etk of prostate cancer cells by a novel dual inhibitor. Cell Death Dis 5:e1409.

15. Wang X, Wong J, Sevinsky CJ, et al. (2016) Bruton's Tyrosine Kinase Inhibitors Prevent Therapeutic Escape in Breast Cancer Cells. Mol Cancer Ther 15:2198-2208.

16. Middendorp S, Dingjan GM, Maas A, Dahlenborg K, Hendriks RW. (2003) Function of Bruton's tyrosine kinase during B cell development is partially independent of its catalytic activity. J Immunol 171:5988-5996.

17. Tumang JR, Negm RS, Solt LA, et al. (2002) BCR engagement induces Fas resistance in primary $B$ cells in the absence of functional Bruton's tyrosine kinase. J Immunol 168:2712-2719.

18. Khare A, Viswanathan B, Gund R, et al. (2011) Role of Bruton's tyrosine kinase in macrophage apoptosis. Apoptosis 16:334-346.

19. Schmidt $U$, van den Akker E, Parren-van Amelsvoort M, et al. (2004) Btk is required for an efficient response to erythropoietin and for SCF-controlled protection against TRAIL in erythroid progenitors. J Exp Med 199:785-795.

20. McNamee HP, Ingber DE, Schwartz MA. (1993) Adhesion to fibronectin stimulates inositol lipid synthesis and enhances PDGF-induced inositol lipid breakdown. J Cell Biol 121:673-678.

21. Honda A, Nogami M, Yokozeki T, et al. (1999) Phosphatidylinositol 4-phosphate 5-kinase alpha is a downstream effector of the small G protein ARF6 in membrane ruffle formation. Cell 99:521-532.

22. Di Paolo G, De Camilli P. (2006) Phosphoinositides in cell regulation and membrane dynamics. Nature 443:651-657. 
23. Lee $\mathrm{KH}$, Feig C, Tchikov V, et al. (2006) The role of receptor internalization in CD95 signaling. EMBO J 25:1009-1023.

24. Chakrabandhu K, Hueber AO. (2016) Fas Versatile Signaling and Beyond: Pivotal Role of Tyrosine Phosphorylation in Context-Dependent Signaling and Diseases. Front Immunol 7:429.

25. Kwiatkowska K. (2010) One lipid, multiple functions: how various pools of $\operatorname{PI}(4,5) \mathrm{P}(2)$ are created in the plasma membrane. Cell Mol Life Sci 67:3927-3946.

26. Chakrabandhu K, Hérincs Z, Huault S, et al. (2007) Palmitoylation is required for efficient Fas cell death signaling. EMBO J 26:209-220.

27. Fais S, De Milito A, Lozupone F. (2005) The role of FAS to ezrin association in FAS-mediated apoptosis. Apoptosis 10:941-947.

28. lessi E, Zischler L, Etringer A, et al. (2015) Death Receptor-Induced Apoptosis Signalling Regulation by Ezrin Is Cell Type Dependent and Occurs in a DISC-Independent Manner in Colon Cancer Cells. PLoS One 10:e0126526.

29. Zhu L, Derijard B, Chakrabandhu K, Wang BS, Chen HZ, Hueber AO. (2014) Synergism of $\mathrm{PI3K} / A k t$ inhibition and Fas activation on colon cancer cell death. Cancer Lett 354:355-364.

30. Gao L, Gülcüler GS, Golbach L, Block H, Zarbock A, Martin-Villalba A. (2016) Endothelial cellderived CD95 ligand serves as a chemokine in induction of neutrophil slow rolling and adhesion. Elife 5. 
a.

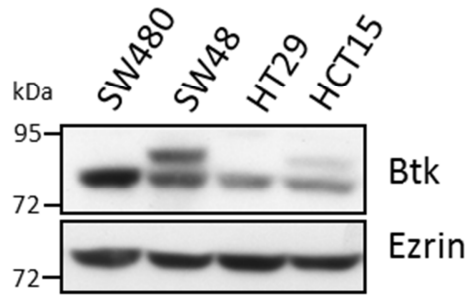

c.

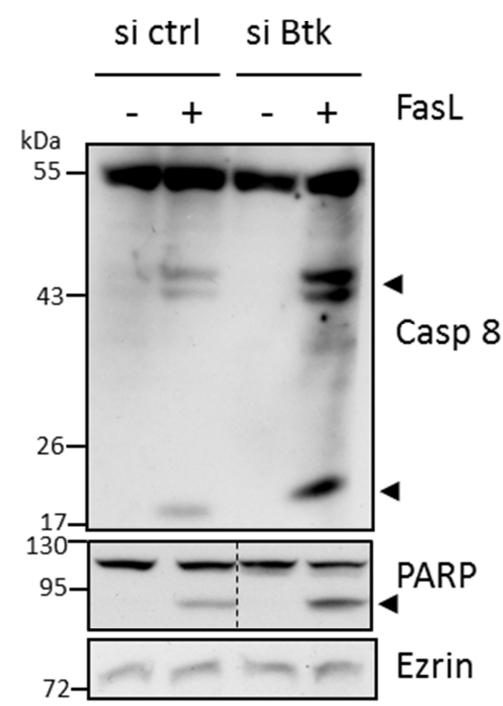

d.

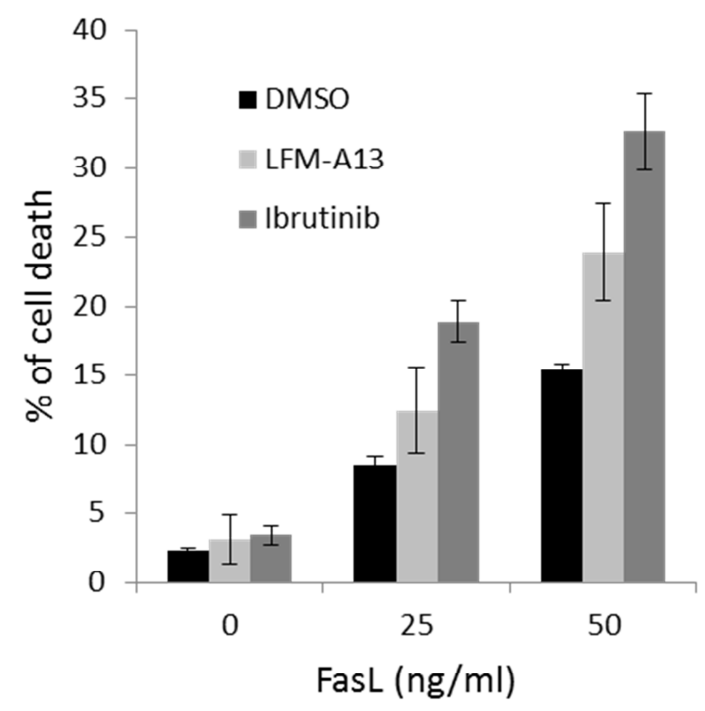

b.

si ctrl si Btk
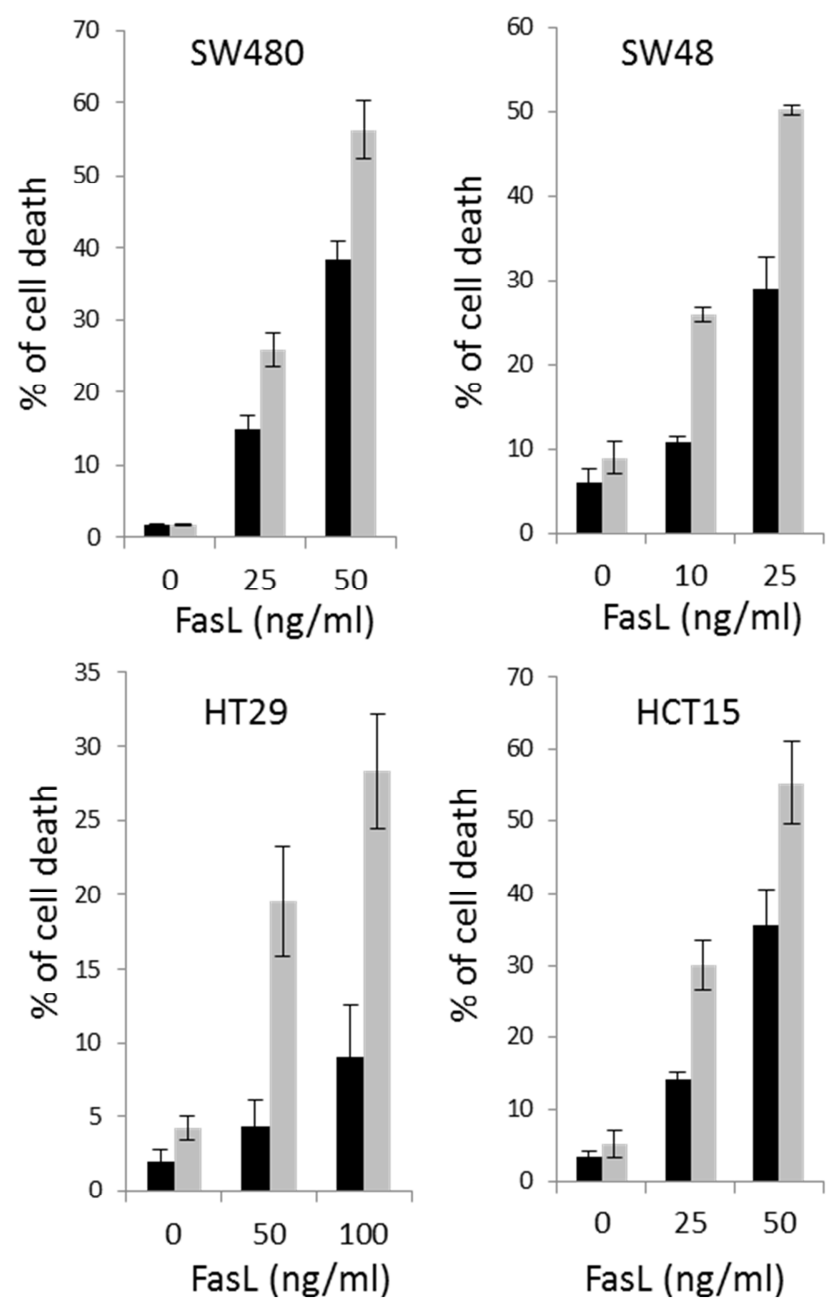

e.

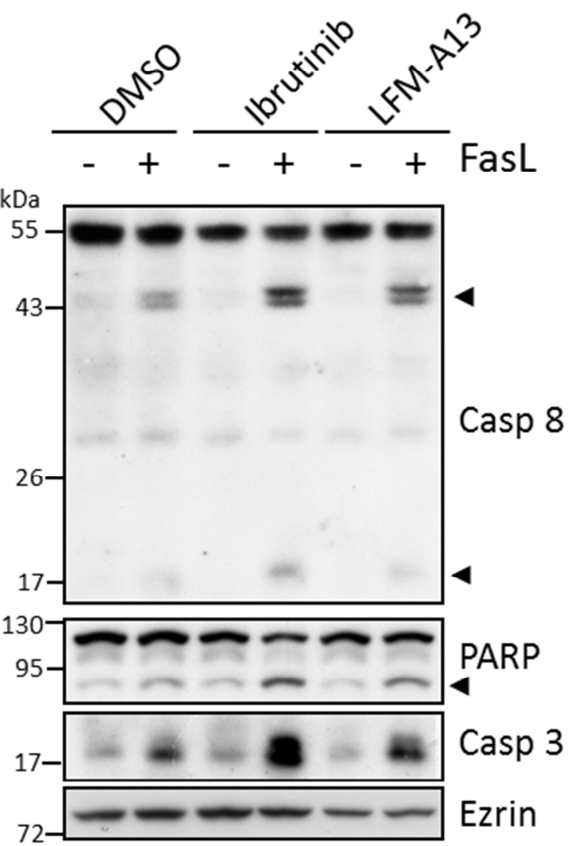

Fig.1 
a.
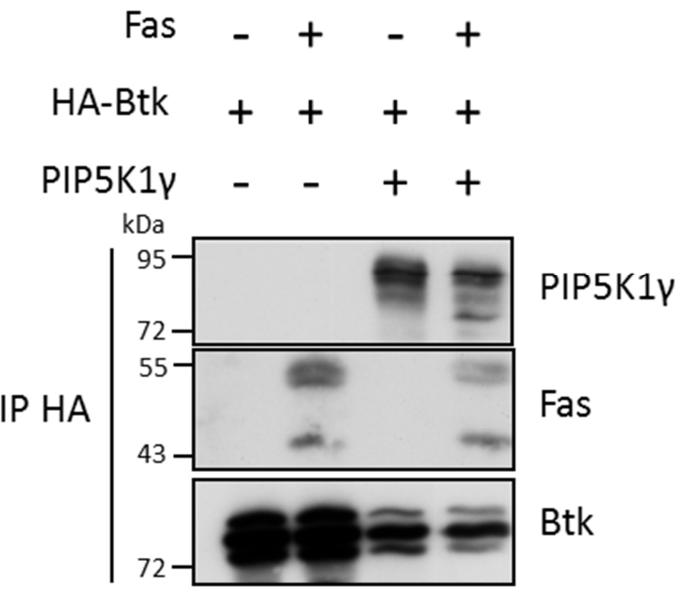

b.
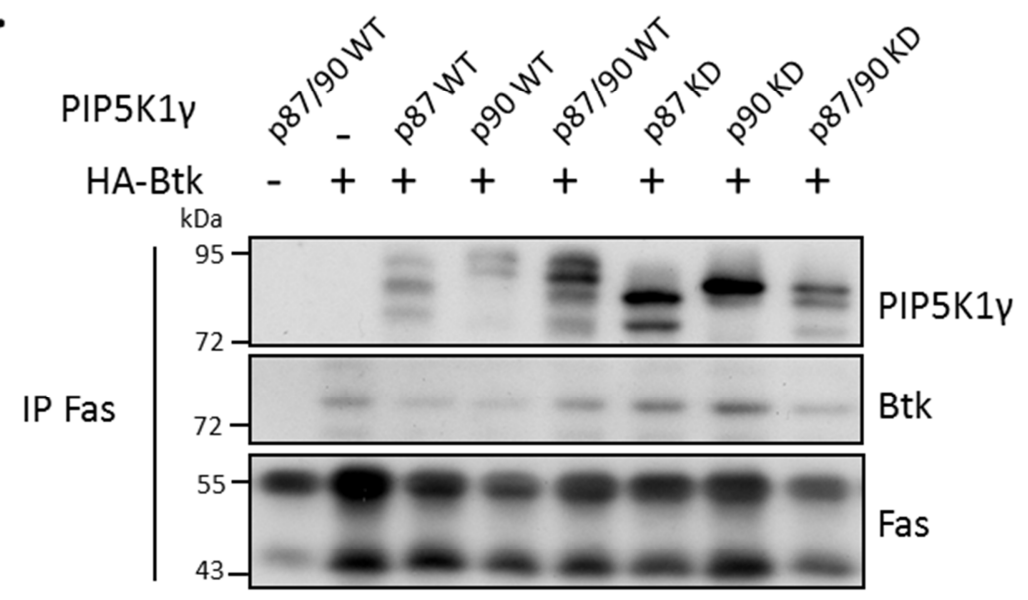

c.

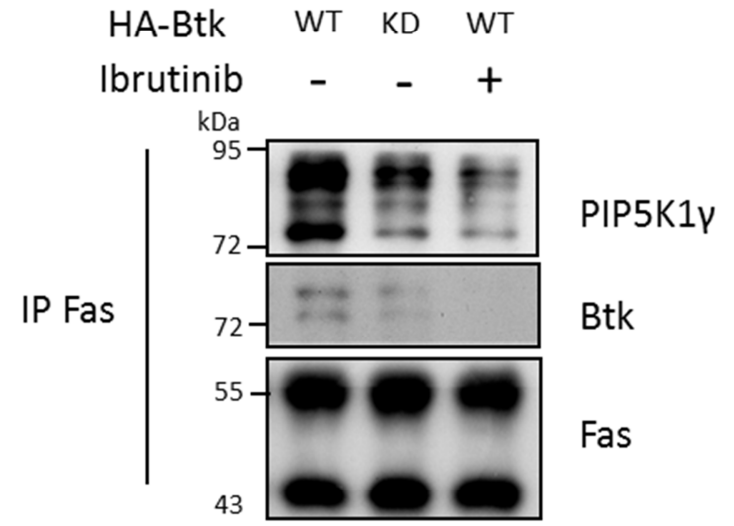

Fig. 2 
a.

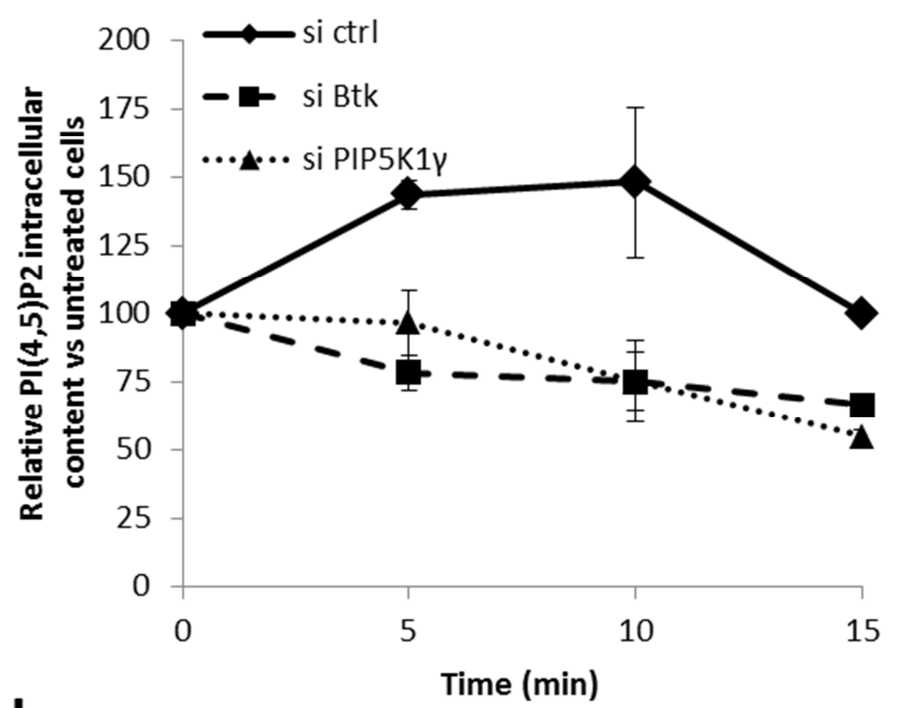

b.

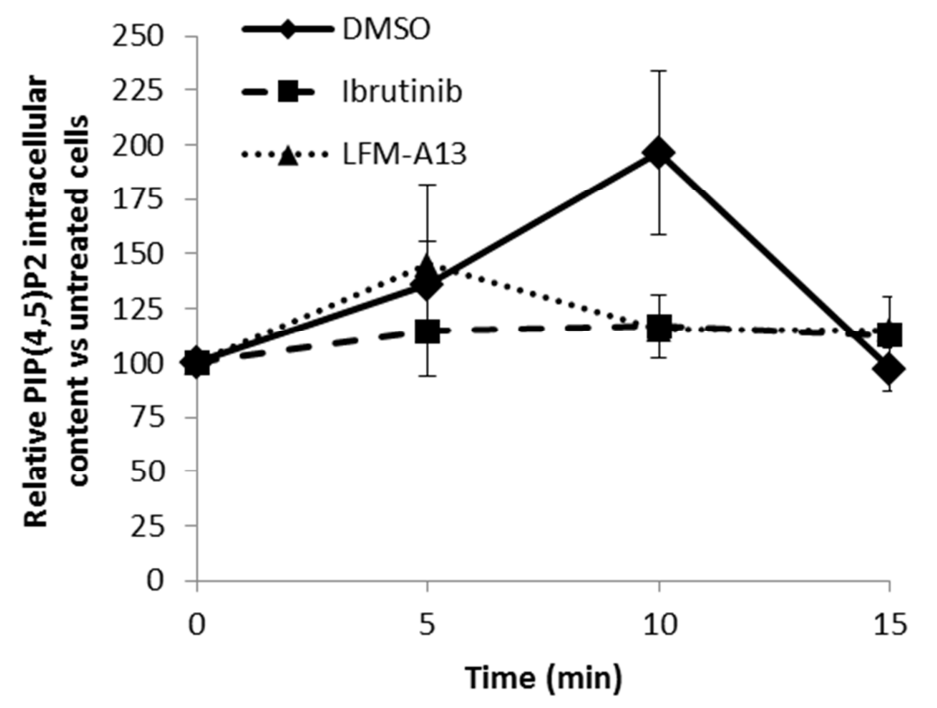

Fig. 3 
a.
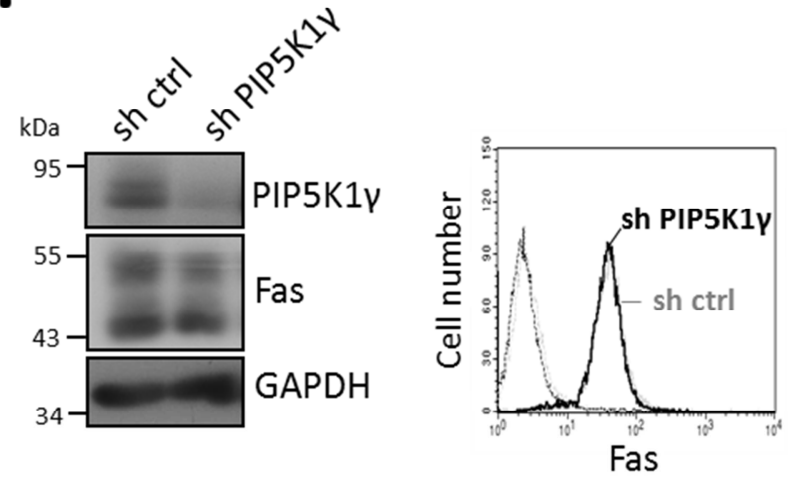

c.

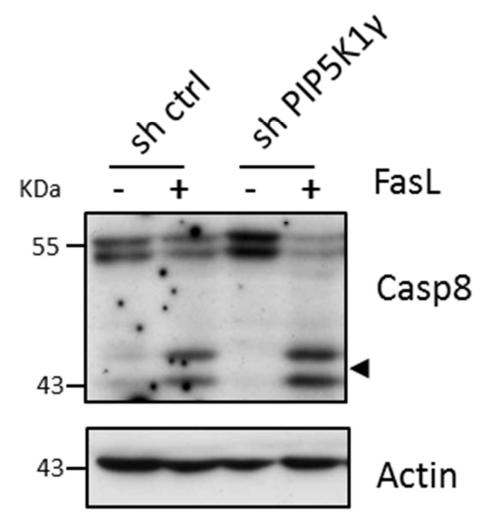

b.

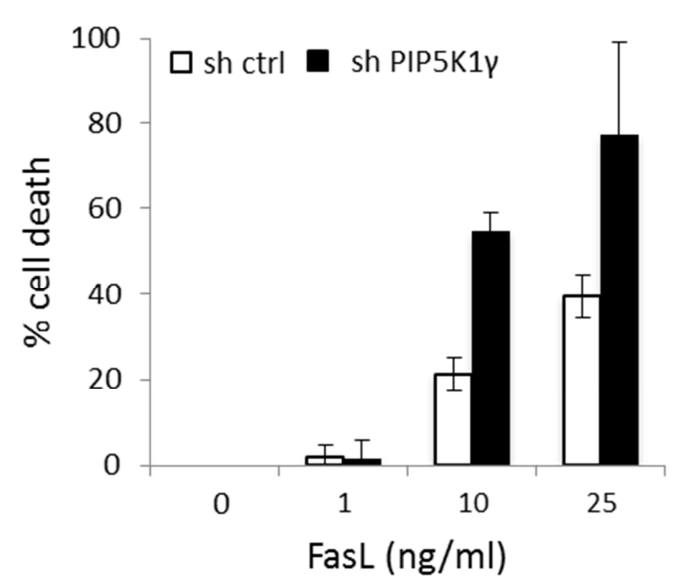

d.

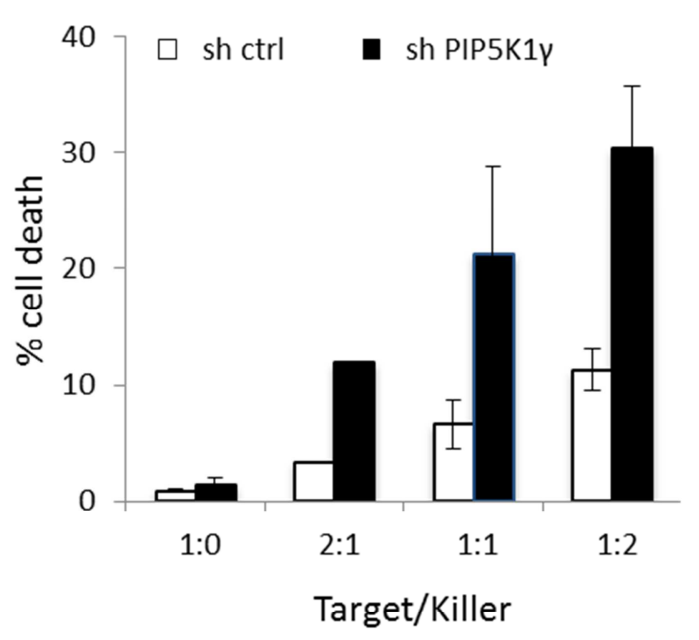

e.

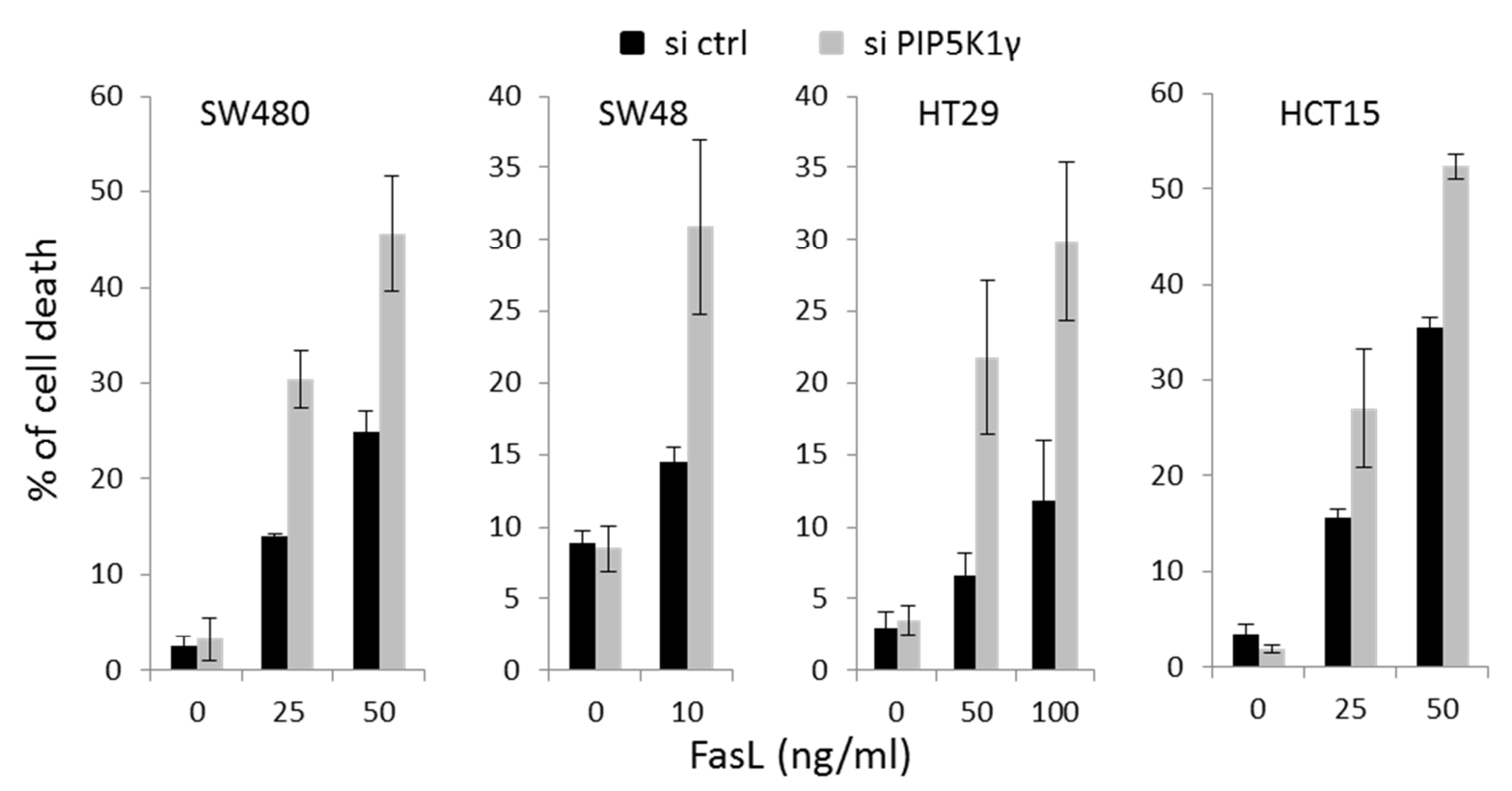

Fig. 4 
a.

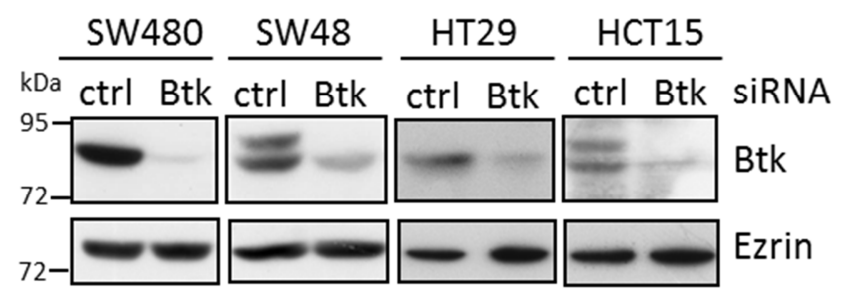

b.

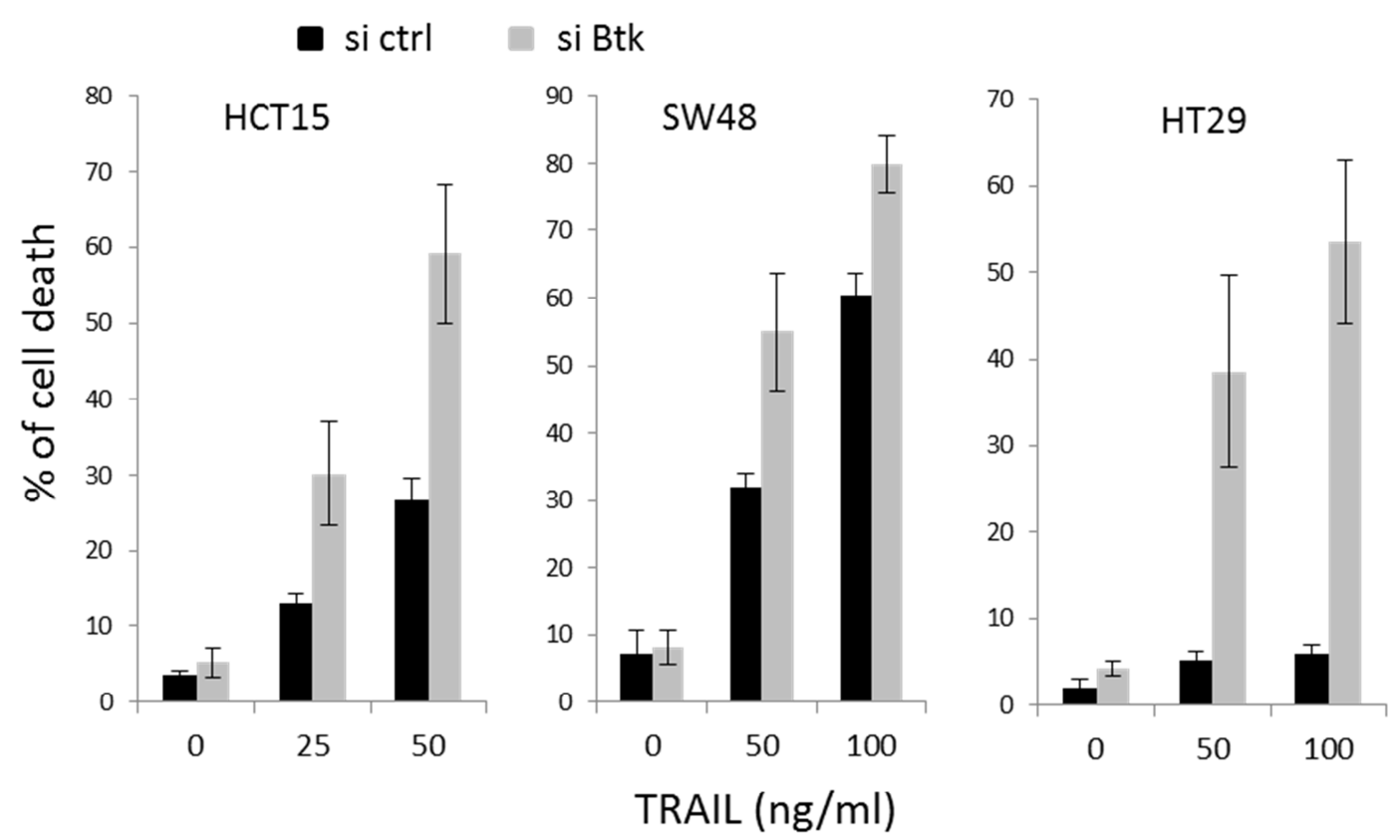

c. - DMSO Ibrutinib $1 \mu \mathrm{M}$ Ibrutinib $3 \mu \mathrm{M}$

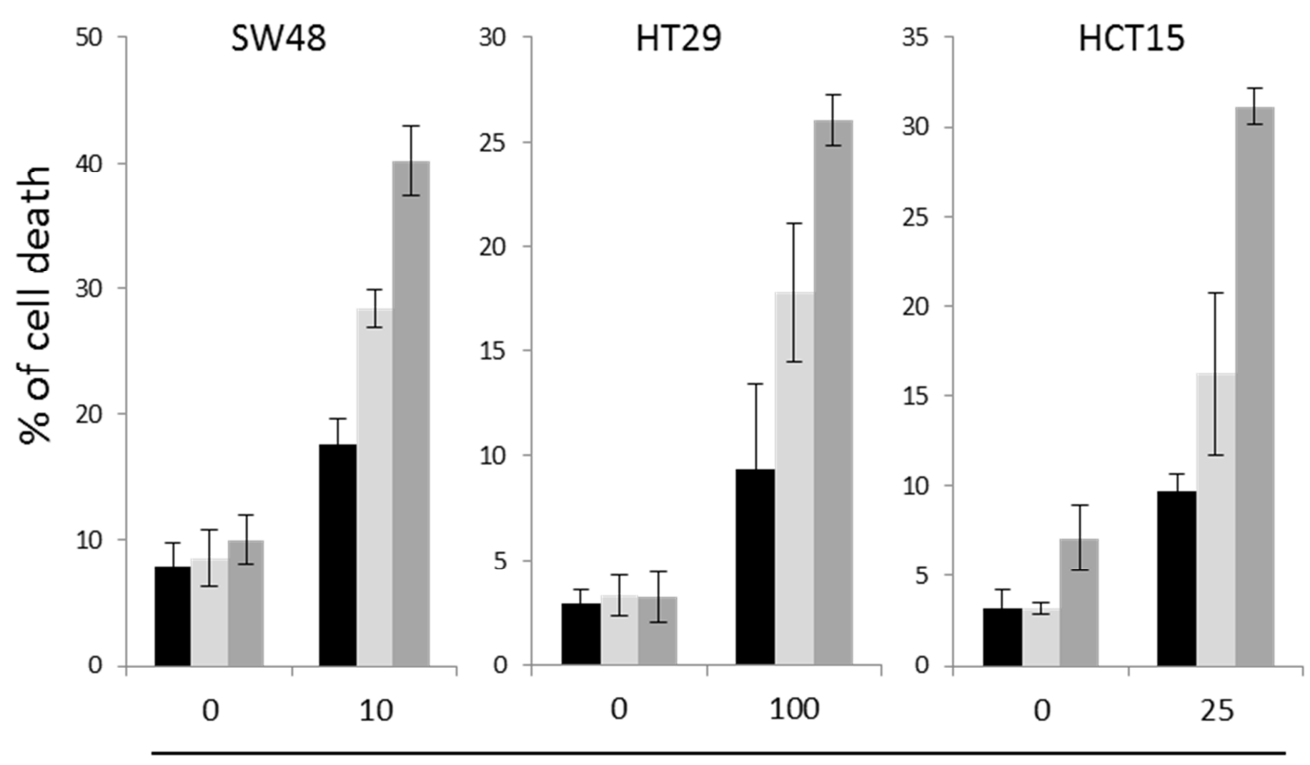

FasL (ng/ml)

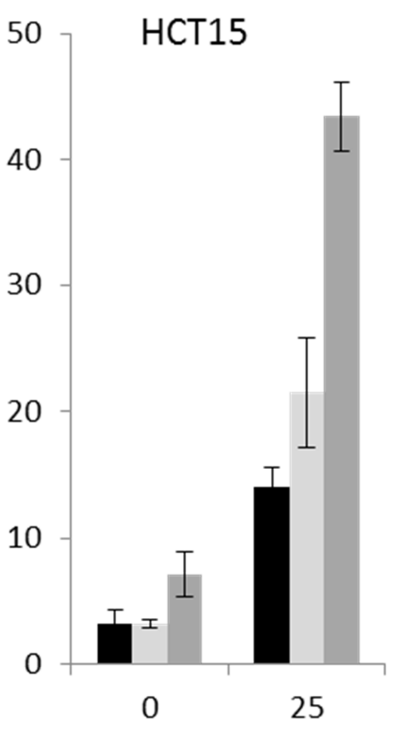

TRAIL (ng/ml) 
a.

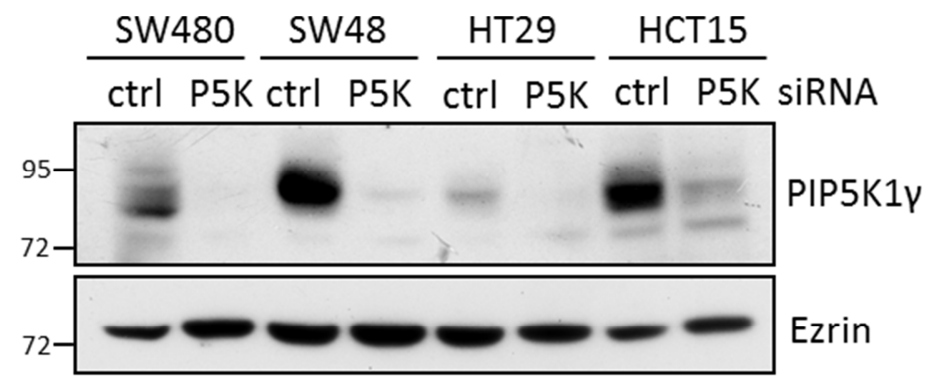

b.

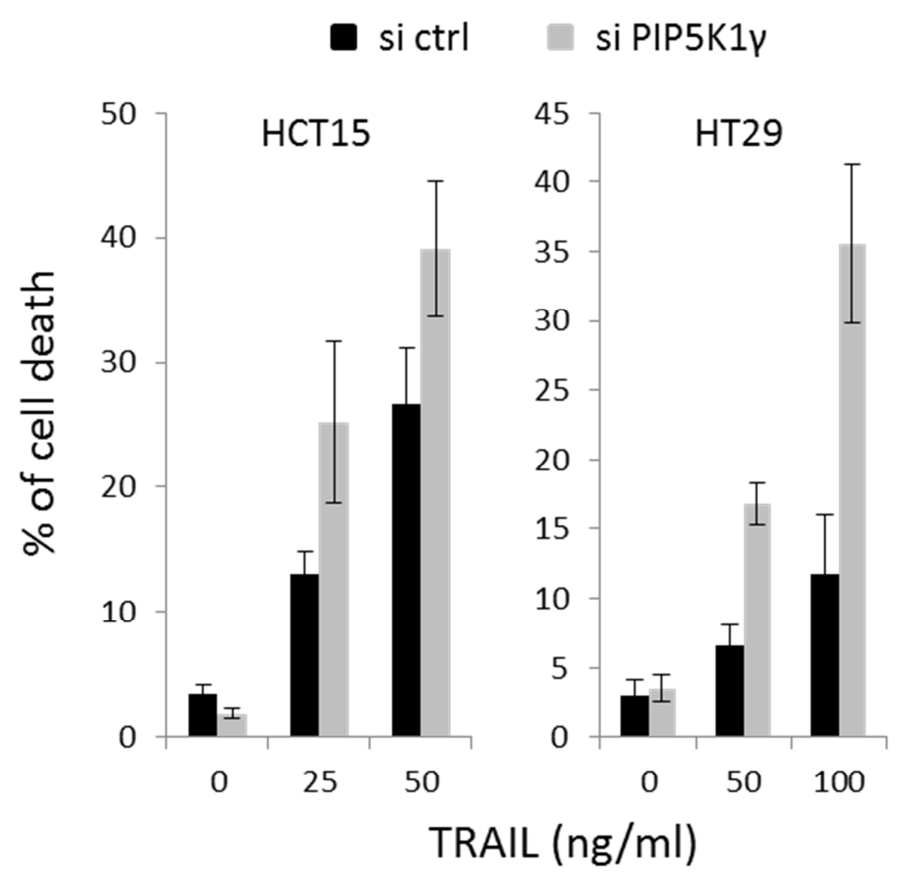

Supplementary Fig.2 